\title{
UNUSUAL PRESENTATION OF NASAL POLYP THAT CLINICALLY SIMULATE A MALIGNANT LESION: A RARE CASE REPORT
}

\author{
V.P. Narve', Kavish Jhawar'2, Manish Kumar Sachan ${ }^{3}$, Freni J.K ${ }^{4}$
}

HOW TO CITE THIS ARTICLE:

VP Narve, Kavish Jhawar, Manish Kumar Sachan, Freni JK. "Unusual presentation of nasal polyp that clinically simulate a malignant lesion: a rare case report". Journal of Evolution of Medical and Dental Sciences 2013; Vol2, Issue 40, October 07; Page: 7664-7667.

ABSTRACT: Nasal polyp is a benign polypoidal lesion which usually arises in maxillary sinus, radiologically opacifying and enlarging the sinus cavity without bone destruction, allergy, chronic sinusitis and cystic fibrosis have all been implicated in the etiology of nasal polyp. Our case is A 37 years old female who presented with bilateral nasal obstruction. Clinical examination and computed tomography shows malignant mass. Under general anaesthesia mass was removed by simple avulsion. Histopathologically, the mass showed benign allergic polyp.

KEY WORDS: Nasal polyp, Malignant mass, Nasopharyngeal mass

INTRODUCTION: Nasal polyps are described as abnormal lesions that emanate from any portion of nasal mucosa or paranasal sinuses. They are typically smooth, round, semi translucent and commonly located along the middle meatus and ethmoid sinus. Nasal polyps are present $1-4 \%$ of the population. They are found more commonly in adults than in children and more commonly in males than in female. ${ }^{1}$

Etiology of nasal polyp has been debated for many years. The prevailing theory is that nasal polyp are formed in response to inflammatory and infectious stimuli. ${ }^{2}$

Nasal polyp may be managed medically and surgically. The most common and preferred medical treatment for nasal polyp is corticosteroid nasally or orally. ${ }^{3}$

CASE REPORT: A 37 year old female presented with complaints of bilateral nasal obstruction and nasal twang of voice since 5 months, which progressively associated with headache, blurring of vision and swelling in mouth since 2 months. There was no history of bleeding from nose, sneezing, allergy and asthma.

Physical examination revealed right deviated nasal septum with no mass in nasal cavity. A pinkish mass present behind the left side of the soft palate, uvula shifted to right side and bulge present on left side of soft palate. Mass was insensitive to touch, does not bleed on touch and surface was irregular. 


\section{CASE REPORT}

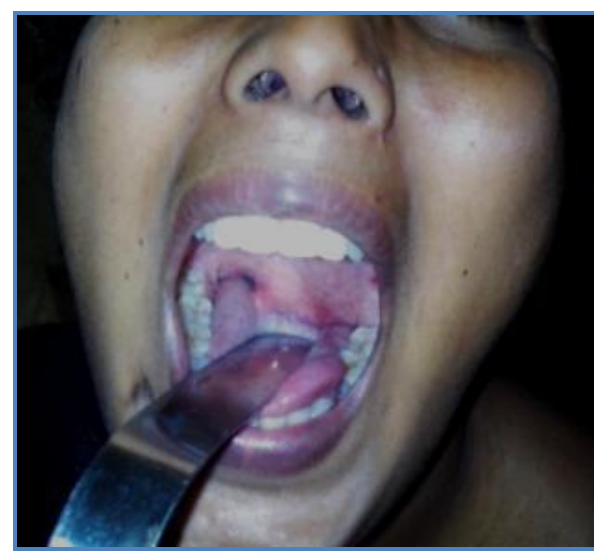

Pre-operative

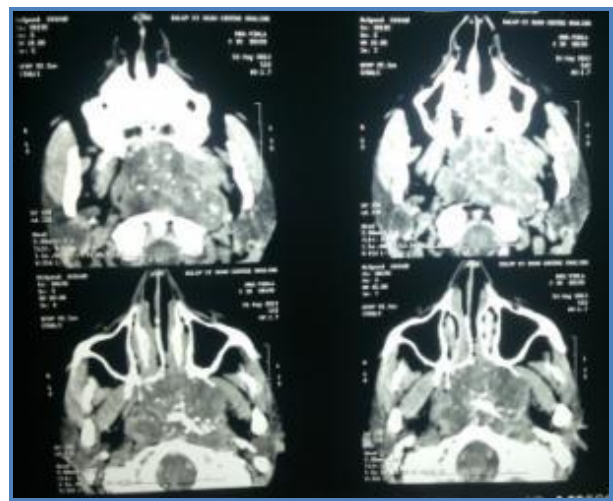

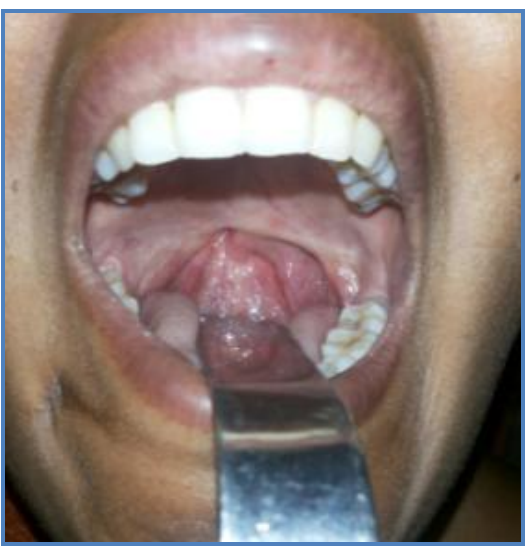

Follow up

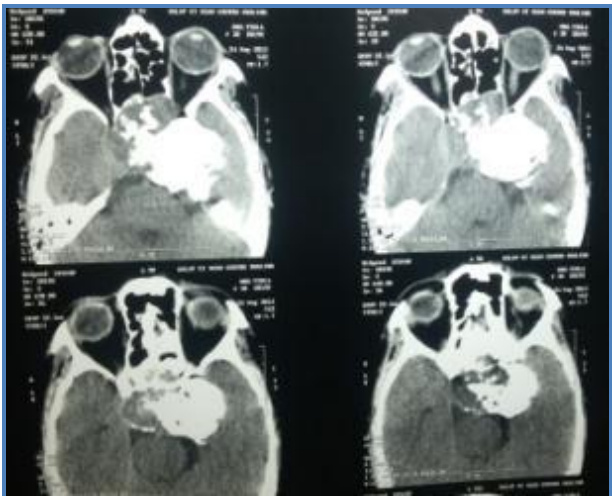

Computed tomography shows soft tissue density heterogenous mass with multiple calcifications is noted in nasopharynx and left parapharyngeal space completely obliterating the nasopharyngeal lumen with near complete effacement of pharyngeal lumen measures about $6.4 *$ $5.4^{*} 3.5 \mathrm{cms}$ at maximum transverse diameter. Superiorly the mass shows erosion/destruction of sphenoid bone/clivus and base of skull with complete opacification of sphenoid sinus. The mass shows intracranial extension involving pituitary fossa and suprasellar cistern region.

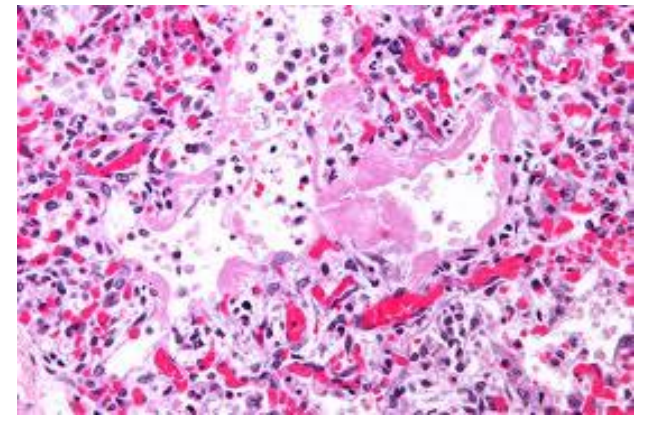

Histopathological Report reveals lack of basement membrane thickening, stroma is less edematous and more fibrotic than inflammatory polyp and large vascular spaces may be present.

DISCUSSION: The antrochoanal polyp is a benign solitary polypoidal lesion that usually arises from maxillary sinus. It passes through the ostium of the sinus into the choana and from there into posterior nasopharynx. ${ }^{4}$ 


\section{CASE REPORT}

Nasal polyp is about $2 \%$ in general population. It increases with age reaching a peak in those aged 50 years and older. The male: female ratio is $2: 1 .^{6}$

The more common symptoms are nasal obstruction, rhinorrhoea, sneezing, headache, epistaxis and anosmia. ${ }^{5}$

Polyp usually show a decrease blood flow and decrease in number of blood vessels compared with nasal mucosa. 7 Approximately 5\% inflammatory or allergic nasal polyp develop extensive vascular proliferation and ectasia with deposition of pseudo amyloid. These so called angiectatic nasal polyp. Can grow rapidly and exhibit an aggressive clinical behavior that could simulate malignancy preoperatively. ${ }^{8}$

The diagnosis is based on anterior rhinoscopy or preferably endoscopy. A computed tomography scan is necessary when malignancy is suspected and before endoscopic surgery. Treatment consists of corticosteroid and severe cases surgery is done. Intranasal corticosteroid reduces rhinitis symptoms, improves nasal breathing, reduce size of polyp and prevent in part there recurrence but it has little effect on the sense of smell. Intra nasal steroids can, as basic long term therapy, be used alone in mild cases and together with systemic steroids and surgery in severe cases. Systemic steroid for 2 or 3 weeks have an effect on all types of symptoms and pathology include the sense of smell. This type of treatment can serve as medical polypectomy. When blockage is the problem in spite of medical treatment, surgery is recommended. Simple polypectomy is still performed but in the more severe and persistent cases endoscopic surgery is recommended. ${ }^{6}$

So in our unusual case, its location was not in the most common area of the nose neither the examination pointed to be a polyp and nor the radiological examination was revealing it to be a polyp.

So radiological study normally confirms the nature of lesion and extent of disease according to CT scan paranasal sinus reports it was misdiagnosed as a malignancy but histology confirmed it to be a polyp.

CONSENT: Written informed consent was obtained from the patient for publication of this case report and accompanying images.

\section{REFERENCES:}

1. Slavin R.G. Nasal polyps and sinusitis Review. JAMA.1997; 278(22):1849-1854.

2. Pawanker R. Nasal polyposis: an update. Curr Opin Allergy Clin Immunol.2003; 3(1): 1-6.

3. Badia L. and Lund V. Topical corticosteroids in nasal polyposis. Drugs.2001; 61(5): 573-578.

4. Towbin R, Duhbar JS, Buvek, Antrochonal poliyp. Am J Roentgenol. 1979: 132(1) 27-31.

5. Tritt S, Mc Main KC, Kountakis SE, Unilateral nasal polyposis: Clinical presentation and pathology. Am J Otolaryngol, 2008; 29(4): 230-232.

6. Scott - Brown's Otorhinolaryngology, Head and Neck surgery vol. II Seventh edition page 1549-1557.

7. Bende M, Flisberg K. Bld flow in nasal polyp. J laryngol Otol. 1985; 99:167-169 doi : 10.1017/S00222151000096468.

8. Yfantis HG, Drachenberg CB, Gray W, Papadinitriou JC. Angiectatic nasal polyps that clinically simulate a malignant process arch pathol lab med 124 (3): 406-410. 


\section{AUTHORS:}

1. V.P. Narve

2. Kavish Jhawar

3. Manish Kumar Sachan

4. Freni J.K.

\section{PARTICULARS OF CONTRIBUTORS:}

1. Associate Professor \& HOD, Department of Otorhinolaryngology, Gajra Raja Medical College, Gwalior, M.P.

2. PG Second Year Student, Department of Otorhinolaryngology, Gajra Raja Medical College, Gwalior, M.P.

3. PG Third Year Student, Department of Otorhinolaryngology, Gajra Raja Medical College, Gwalior, M.P.
4. PG Second Year Student, Department of Otorhinolaryngology, Gajra Raja Medical College, Gwalior, M.P.

\section{NAME ADDRESS EMAIL ID OF THE CORRESPONDING AUTHOR:}

Dr. V.P. Narve,

Associate Professor \& HOD,

Department of ENT,

G.R. Medical College \& J.A Group of Hospitals, Gwalior, M.P. - 474009.

Email-drvpnarve@gmail.com

Date of Submission: 24/09/2013.

Date of Peer Review: 25/09/2013.

Date of Acceptance: 25/09/2013.

Date of Publishing: 01/10/2013 